\title{
Pattern of congenital heart diseases among clinically diagnosed Down's syndrome children
}

1 Dr. Abu Sayed Munsi Assistant Professor Dept. of Paediatric Cardiology BICH, Dhaka Shishu Hospital

2 Prof. Manzoor Hussain Professor and Head Dept. of Paediatric Medicine \& Cardiology, BICH

Dhaka Shishu Hospital

${ }^{3}$ Dr. Rezoana Rima Assistant Professor Dept. of Paediatric Cardiology, BICH, Dhaka Shishu Hospital

${ }^{4}$ Dr. Robi Biswas Assistant Professor Department of Endocrinology, BICH, Dhaka Shishu Hospital

${ }^{5}$ Dr. Salahuddin Mahmud Assistant Professor Dept. of Gastroenterology, BICH, Dhaka Shishu Hospital

${ }^{6}$ Dr. Abu Sayeed Registrar, Department of Cardiology Dhaka Shishu Hospital

\section{Correspondence}

Dr. Md. Abu Sayed Munsi Assistant Professor Dept. of Paediatric Cardiology, BICH Dhaka Shishu Hospital, Dhaka E- mail : sayedmn11@gmail.com

\section{A S Munsi ${ }^{1}$, M Hussain ${ }^{2}$, R Rima $^{3}$, R Biswas ${ }^{4}$, S Mahmud ${ }^{5}$, A Sayeed ${ }^{6}$}

\section{Abstract}

Background : Down's syndrome (DS) is the commonest genetic cause of malformation with congenital heart defects.

Objectives : This study was conducted to evaluate the frequency of various congenital heart defects in children with clinically diagnosed Down's syndrome in Dhaka Shishu Hospital.

Material \& Methods : This prospective study was conducted at Pediatric cardiology department of Dhaka Shishu Hospital from $1^{\text {st }}$ February 2013 to $31^{\text {st }}$ January 2014. Admitted Seventy four phenotypically Down's syndrome patients were included in this study. After taking detailed history and physical examination, all these patients were subjected to Color Doppler echocardiography in addition to routine laboratory investigations.

Results : Total 74 down's Syndrome patients were admitted at cardiology department during the study period. Among them 35 $(47.29 \%)$ were males and $39(52.71 \%)$ were females with male to female ratio of 1:1.12. Atrioventricular septal defect was the commonest defect $15(20.27 \%)$, followed by Ventricular septal defect $12(16.21 \%)$, Patent ductus arteriosus $11(14.86 \%)$, Atrial septal defect $7(9.46 \%)$, Tetralogy of Fallots $3(4.05 \%)$, Pentology of Fallots $2(2.70 \%)$, Dextrocardia with D-TGA $1(1.35 \%)$, Total anomalous pulmonary venous drainage $1(1.35 \%)$ but Multiple congenital heart disease were 22(29.72\%) cases. Along with congenital heart disease $3(4.05 \%)$ patients had GIT abnormality, $4(5.4 \%)$ patient had congenital hypothyroidism and 3(4.05\%) patients had Eye problem.

Conclusion : Congenital heart defects are common in children with Down's syndrome. The commonest one is Atrioventricular septal defect in our set-up.

Key words : Down's Syndrome, Atrioventricular septal defect, Ventricular septal defect, Congenital hypothyroidism.

\section{Introduction}

Down's syndrome (DS) is also called Trisomy 21 , is the commonest genetic pattern of malformation inhuman being ${ }^{1}$. Most of the textbooks and authors quote the incidence of this malformation as one in 700 to 800 live births. Down's syndrome was first described by John Langdon Haydon Down with characteristic physical features and problems and so known as Down's syndrome. ${ }^{1}$ Children with Down's syndrome are at much higher risk of congenital heart disease. $^{2}$ The incidence of congenital heart disease (CHD) in general population is 0.8 percent whereas the incidence of CHD in children with Down's syndrome (DS) is between $40-60$ percent. $^{3}$ The recurrence risk in the general population is $1 \%$. Children with DS have typical physical phenotype of mental retardation, brachycephaly, hypotonia, flat facies, slanted palpebral fissures, epicanthic folds, brush field spots on the iris, relatively large protruding tongue, small low set ears and hand anomalies (short and broad hand, clinodactyly ofthe fifth finger, Simian crease). ${ }^{6-8}$ Congenital heart defects, seizures, strabismus, nystagmus, atlantoaxial instability, cryptorchidism, increased risk of leukemia, dementia, duodenal atresia and hypothyroidism are usually associated with DS. Although there is variability in the clinical features, the constellation of phenotypic features is fairly consistent and permits clinical recognition of trisomy $21.4,6-8$

Congenital heart disease (CHD) is, without a doubt, the main factor contributing to a favorable or unfavorable course in these patients. Among all cases of CHD, $4-10 \%$ are associated with DS. ${ }^{4,5,9}$ CHD is the greatest cause of death in patients with DS during the first two years of life. ${ }^{10}$ The cardiac lesions can be single or multiple. Common CHDs are Atrioventricular septal defect (AVSD), Ventricular septal defect (VSD), Atrial septal defect (ASD), Patent ductus arteriosus (PDA) and Tetralogy of Fallot (TOF). ${ }^{4}$ These children are frequently associated with pulmonary hypertension which is also one of the determining factor for the management of CHD.

This study was conducted to evaluate the frequency of various types of congenital heart defects found in Down's syndrome children at Dhaka shishu hospital.

\section{Materials and Methods}

A prospective study was carried out to all the children with down syndrome admitted in pediatric cardiology inpatient department (Indoor) at DSH over the period of one year from $1^{\text {st }}$ February 2013 to $31^{\text {st }}$ January 2014. Dhaka Shishu Hospital which is a tertiary care hospital and largest children hospital in Bangladesh having specialized cardiac department. Down syndrome was diagnosed clinically with their typical features. Patients with dysmorphic features other than Down syndrome were excluded from the study. Karyotyping was done whenever feasible. Detailed history and physical examination of every DS child were carried out. The exact age of the mother was recorded. The Physical findings to look in these children include: mongoloid facies, brachycephaly, depressed nasalbridge, protruding tongue, small low set ears, upward slantedeyes with epicanthal fold, short neck, short and broad hands, transverse single 
palmar crease, hypotonia and delayed milestones. Chest x-ray, ECG and Color Doppler Echocardiography were done. As hypothyroidism was frequently associated with downsyndrome, thyroid function test (TFT) was also included in the study. All the collected data were entered into and analysed by SPSS statistical software (version 14). Descriptive statistics (mean, median and proportion) were obtained.

\section{Results}

Among 74 patients with Down's syndrome, 35 (47.29\%) were males and $39(52.71 \%)$ were females with male to female ratio of $1: 1.12$ (Table-1).

Table 1: Sex distribution of patients / (total no $=74$ )

$\begin{array}{lcc}\text { Sex } & \text { Number } & \text { Percentage (\%) } \\ \text { Male } & 35 & 47.29 \% \\ \text { Female } & 39 & 52.71 \%\end{array}$

Thirty three (44.59\%) cases were in 0-6 month's age, 26 (35.13\%) cases were in more than 6 months to 1 years age,14 (18.91\%) cases were in more than 1 years to 5 years age and $1(1.35 \%)$ cases were in more than 5 years age (Table - 11).

Table-II : Age distribution of patients $(n=74)$

$\begin{array}{lcc}\text { Age } & \text { Number } & \text { Percentage } \\ 0-6 & 33 & 44.59 \% \\ >6 \text { months to } 1 \text { yrs } & 26 & 35.13 \% \\ >\text { 1years to } 5 \text { yrs years } & 14 & 18.91 \% \\ >5 \text { years } & 1 & 1.35 \%\end{array}$

The sample distribution according to maternal age during the patient's gestation period, we found that $33(44.59 \%)$ of the mothers were $>30$ 35years old. Most mothers were multiparas (93.24\%)

\section{Table III : Sample distribution according to reproductive characteristics of mothers}

$\begin{array}{lcc}\begin{array}{l}\text { Variable } \\ \text { Maternal age during }\end{array} & \text { number } & \text { Percentage (\%) } \\ \text { pregnancy (years) } & & \\ 25 & 10 & 13.51 \% \\ >25-30 & 24 & 32.43 \% \\ >30-35 & 33 & 44.59 \% \\ >35 & 7 & 9.45 \% \\ \text { Parity } & & \\ \text { Primiparity } & 5 & 6.76 \% \\ \text { Multiparity } & 69 & 93.24 \% \\ \text { Total } & & 74100\end{array}$

Table IV shows Clinical findings in Down's syndrome cases. Developmental delay was present in 74 (100\%) cases; History of recurrent respiratory tract infection was present in 65 (87.84\%) cases; G-I Tract abnormality 3 (4.05\%) cases; Congenital Hypothyroidism was present in $4(5.40 \%)$ cases; Eye problem $3(4.05 \%)$ and Infective endocarditis 1 ( $1.35 \%)$ cases.
Table IV : Non Cardiac Medical problem in study patient ( $n=74)$

$\begin{array}{lcc}\text { Symptoms and signs } & \text { No } & \text { Percentage } \\ \text { Developmental delay } & 74 & 100 \% \\ \text { H/O Recurrent RTI } & 65 & 87.84 \% \\ \text { G I Tract abnormality } & 3 & 4.05 \% \\ \text { Congenital Hypothyroidism } & & 45.40 \% \\ \text { Eye problem } & 3 & 4.05 \% \\ \text { Infective endocarditis } & 1 & 1.35 \%\end{array}$

This study showed that most common form of CHD was Atrioventricular septal defect (AV Canal) found in $15(20.27 \%)$ of the 74 children followed byVentricularseptal defect (VSD) 12 (16.21\%), Patent ductus arteriosus (PDA) 11 (14.86\%), Secundum Atrial septal defect (ASD) 7 $(9.46 \%)$ and multiple congenitalheart defects in $22(29.72 \%)$ children. Cyanotic congenital heart defects include Tetralogy of Fallots (TOF) in 3 $(4.05 \%)$, pentology of Fallots in2 $(2.70 \%)$, Total anomalouspulmonary venous drainage (TAPVD) and Dextrocardia with D- TGA each in I $(1.35 \%)$ (Table v).

Table V: Type of congenital heart defects inchildren with Down's syndrome

\begin{tabular}{|c|c|c|c|}
\hline SI. No. & Type of cardiac defect & No. & Percentage \\
\hline 1 & Atrioventricular septal defect & 15 & $20.27 \%$ \\
\hline 2 & Ventricular septal defect & 12 & $16.21 \%$ \\
\hline 3 & Patent ductus arteriosus & 11 & $14.86 \%$ \\
\hline 4 & Atrial septal defect & 7 & $9.46 \%$ \\
\hline \multirow[t]{7}{*}{5} & Multiple cardiac lesions & & \\
\hline & ASD + VSD $(n=10)$ & & \\
\hline & ASD + VSD+ PDA $(n=4)$ & & \\
\hline & $A S D+\operatorname{PDA}(n=3)$ & & \\
\hline & VSD + PDA $(n=3)$ & 22 & $29.72 \%$ \\
\hline & VSD + AS $\quad(n=1)$ & & \\
\hline & $P D A+P S \quad(n=1)$ & & \\
\hline 6 & Tetralogy of Fallots & 3 & $4.05 \%$ \\
\hline 7 & Pentology of Fallots & 2 & $2.70 \%$ \\
\hline \multirow[t]{2}{*}{8} & Total anomalous pulmonary venous & & \\
\hline & drainage & 1 & $1.35 \%$ \\
\hline 9 & Dextrocardia with D- TGA & 1 & $1.35 \%$ \\
\hline
\end{tabular}

\section{Discussion}

Seventy four children with clinically diagnosed down's syndrome were admitted in cardiology department over the period of one year. All were included in the study. Down Syndrome (DS) is a major cause of congenital heart disease (CHD) and the most frequent known causes of Atrioventricular septaldefects (AVSDs). ${ }^{22}$ Advanced maternal age is associated with a high incidence of Trisomy ${ }^{21}$, however our study showed it is more frequent in young mothers as they have overall high birth rate. The finding is similar to studies by Karen Summar, et $\mathrm{al}^{4}$ and De Rubens Figueroa J, et al. ${ }^{5}$

The present study found, among 74 CHD patients, 64 (86.48\%)had isolated cardiac defect, which is similar to the studyinGuatemala, ${ }^{10}$ however it is different as compared to $65 \%$ in libya ${ }^{9}, 74 \%$ in Mexico ${ }^{5}$, 
$78 \%$ in Turkey ${ }^{11}$. AVSD was the most common isolated defect and was found in $15(20.27 \%)$ of the 74 patients which was followed by VSD 12 (16.21\%) then PDA $11(14.86 \%)$ and ASD 7 (9.56\%).These findings are consistent with the study in Bangladesh ${ }^{1}$, I taly ${ }^{12}$, USA $^{13}$ and Sudan ${ }^{14}$ where AVSD was the most common isolated congenital cardiac defect followed by VSD then PDA and ASD (Table VI) But these findings differ if we compared with the study inChina ${ }^{15}$, Saudi Arabia ${ }^{16}$ and Guatemala 10 where VSD being the most common followed by ASD and AVSD. However in the study in India ${ }^{17}$ ASD was more common than AVSD. The study in Mexico ${ }^{5}$ and Libya ${ }^{5}$ ASD was the most common followed by VSD and AVSD or PDA.

The cardiac defects in DS are commonly single but they may be multiple as well. The single

cardiac lesions represented $70.28 \%$ of all CHD in our study compared with $65 \%$ in Libya, $80 \%$ in Guatemala ${ }^{10}, 74 \%$ in Mexico 5 and $78 \%$ in Turkey ${ }^{18}$. This difference may be because of age at diagnosis where patients with more complex lesions die earlier before diagnosis. Multiple cardiac defects were present in $29.72 \%$ cases in our study. We found ASD and VSD as the most common cardiac defect associated with other lesions. This finding is similar to that of Elmagrpy et al. ${ }^{18}$

The most common cyanotic CHDs in this study was TOF occurring in $4.05 \%$. This frequency is relatively similar to that reported by Caucasian $(4 \%)^{19}$ and Saudi Arabian children $(5.3 \%)^{20}$ but lower to that reported by other workers $(16 \%)^{17}(13 \%) .{ }^{15}$ The frequency and distribution of CHD in DS vary in different geographical regions, the reason for this difference is not clear, although some consistency was observed between certain global areas. This variation in geographical distribution maybe caused by numerous factors, one of which could be the genetic make-up of each nation or global region or it could be due to specific embryological mechanisms.

Non cardiac medical problems associated with Down's syndrome found in this study were-

a) Developmental delay in $100 \%$ cases b) Recurrent RTIin $87.84 \%$ cases c) G-I tract abnormality in $4.05 \%$ casesd) Congenital hypothyroidism in $5.40 \%$ cases e) Eye problem in $4.05 \%$ cases. Other study showed $100 \%$ developmental delay, $2 \%-5 \%$ gastrointestinal abnormalities, $60 \%$ eye disorder and $5 \%$ has thyroid disorders 21,22 . Most Cardiologist would agree that all Down's Syndrome babies should have a cardiac evaluation because of the high incidence of associated congenital heart defects. In our center, we do screening of all babies with Down's syndrome for congenital heart disease and thyroid disorders.

\section{Conclusion}

Though large volume of cardiac patients visited or are being referred here, we cannot extrapolate the result as nation-wise scenario as there are still many cases who are under the tip of ice-berg. They are under diagnosed because either they have not been visited to primary care physician or the socioeconomic status of parents does not allow them to consult with physician. The sample size is small as compared to other similar studies. Cytogenetic studies were not routinely performed on all patients because of financial problem of parents. Diagnosis was mainly based on clinical grounds. Further studies are recommended with larger sample size.

\section{References}

1. Fatema NN. Down's syndrome with congenital heart disease: Analysis of cases over two years in a non- invasive laboratory of a tertiary hospital. Cardiovasc. j. 2010; 2(2): 184187.

2. Judith G. Hall. Chromosomal clinical abnormalities. In: Richard E Behrman, Robert M. Kliegman, Hal B Jenson. Eds. Nelson textbook of Paediatrics. Philadelphia: WBSaunders, 2000: 328-329.

3. Ronald. V. Lacro. Dysmonorphology. In: Donald C. Fyler MD. Eds. Nadas' Pediatric Cardiology. Philadelphia: Hanley and Belfus, 1992: 41-47.

4. Karen S, Brendan L. Down Syndrome and Other Abnormalities of Chromosome Number. In: Kliegman, Behrman, Jenson, Stanton, editors. Nelson textbook of Pediatrics. 19th edition. Philadelphia: Saunders Elsevier; 2007; 400.

5. De Rubens Figueroa J, del Pozzo Magaña B, Pablos Hach JL, et al. Heart malformations in children with Down syndrome. Rev Esp Cardiol 2003; 56: 894-9.

6. Mohammad A, Khan I, Khan MQ. Hypothyroidism in children with Down's syndrome: A hospital based study. Gomal J ournal of Medical Sciences 2012; 10: 96-9.

7. Chandra N, Cyril C, Lakshmi narayana P, et al. Cytogenetic Evaluation of Down Syndrome: A Review of 1020 Referral Cases. Int J Hum Genet 2010;10: 87- 93.

8. Devlin L, Morrison PJ. Accuracy of the clinical diagnosis of Down syndrome. Ulster Med J 2004; 73: 4- 12.

9. Elmagrpy Z, Rayani A, Shah A, et al. Down syndrome and congenital heart disease: why the regional difference as observed in the Libyan experience? Cardiovasc J Afr 2011; 22: 306-9.

10. Vida VL, Barnoya J, Larrazabal LA, et al. Congenital cardiac disease in children with Down's syndrome in Guatemala. Cardiol Young 2005; 5: 286-90.

11. Nisli K, Oner N, Candan S, et al. Congenital heart disease in children with Down's syndrome: Turkish experience of 13 years. Acta Cardiol 2008; 63: 585-9.

12. Placidi S, Digilio MC, Marino B. Types of cardiac defects in children with Down's syndrome. Cardiol Young 2006; 6: 198-9.

13. Freeman SB, Taft LF, Dooley KJ, et al. Population based study of congenital heart defects in Down syndrome. AmJ Med Genet 1998; 80: 213-7.

14. Ali SK. Cardiac abnormalities of Sudanese patients with Down's syndrome and their short-term outcome. Cardiovasc J Afr 2009; 20: 112-5.

15. Lo NS, Leung PM, Lau KC, et al. Congenital cardiovascular malformations in Chinese children with Down's syndrome. Chin Med J (Engl). 1989; 102: 382- 6.

16. Abbag FI. Congenital heart diseases and other major anomalies in patients with Down syndrome. Saudi Med J 2006; 27: 219-22.

17. Kava MP, Tullu MS, Muranjan MN, et al. Down syndrome: clinical profile from India. Arch Med Res 2004; 35: 31-5.

18. Elmagrpy Z, Rayani A, Shah A, Habas E, Aburawi EH. Down syndrome and congenital heart disease: why the regional difference as observed in the Libyan experience? Cardiovasc J Afr 2009; 20: 112-5.

19. Freeman SB, Taft LF, Dooley KJ, Allran K, Sherman SL, Has sold TJ, et al. Populationbased study of congenital heart defects in Down syndrome. Am J Med Genet 1998; 80: 213-7.

20. Abbag FI. Congenital heart diseases and other major anomalies in patients with Down's syndrome. Saudi Med J 2006; 27: 219-22.

21. Barlow GM, Chen XN, Shi Zy, Lyons GE, Kurnit DM, Celle L et al. Down's Syndrome and congenital heart disease: a narrowed region and a candidate gene. GenetMed2001; 3(2): 91-101.

22. Cullum L, Liebman J. The association of congenital heart disease with Down's Syndrome. J Am Col Cardiol 1969; 24 (3): 354-357. 